\title{
THE INCIDENCE OF STORAGE ROTS AFTER POSTHARVEST APPLE WASHING
}

\author{
R.W.A. SCHEPER ${ }^{1}$, D.J. ROGERS ${ }^{1}$, J.T.S. WALKER ${ }^{1}$, \\ M.A. MANNING ${ }^{2}$ and P.N. WOOD ${ }^{1}$ \\ ${ }^{1}$ HortResearch, Private Bag 1401, Havelock North, New Zealand \\ ${ }^{2}$ HortResearch, Private Bag 92 169, Auckland, New Zealand
}

Corresponding author: rscheper@hortresearch.co.nz.

\begin{abstract}
The effect of four postharvest apple washing treatments and two unwashed treatments on fruit surface microflora and the development of storage rots in punctured and uninjured fruit were assessed. A significantly higher incidence of storage rot was observed in punctured apples (16-35\%) than in uninjured apples (1-3\%) after washing in water with high fungal populations $(\mathrm{P}<0.01)$. In contrast, no significant difference in rot incidence was observed between punctured (2\%) and uninjured apples (1\%) when the apples were washed in water containing few fungi. Most rots (90\%) were apparently caused by Penicillium spp. Rots with Mucor spp., Botrytis spp. and Alternaria spp. were also present. Significant relationships were identified between (a) fungal concentrations in wash water and storage rot incidence in punctured apples, (b) post-washing fruit surface fungal populations and storage rot incidence in punctured apples and (c) fungal concentrations in wash water and fruit surface fungal concentrations. Yeast populations had no effect on rot incidence.
\end{abstract}

Keywords: apple, postharvest, washing, storage rot, decay, Penicillium, fungi, yeast.

\section{INTRODUCTION}

Postharvest apple washing equipment has been used in New Zealand since 2000, as a phytosanitary treatment, e.g. to remove mealybug and mummies of woolly apple aphid (J.T.S. Walker, pers. comm.). However, postharvest washing treatments have been shown to affect storage rots in both tomatoes and pears. Tomato decay increased as the concentration of soft rot bacteria (Erwinia carotovora) in washing water increased (Bartz 1999) and, in a preliminary study, pear storage rot incidence and severity increased in direct proportion to water pressure at the washer nozzles (Spotts et al. 2006). It is, therefore, possible that postharvest apple washing increases storage rots in apples. In particular, the concentration of fungi and yeasts in the washing water, may affect storage rots in apples by changing the microflora on the apple surface.

The objective of this study was to determine the effect of postharvest treatments involving apple washing on (a) the subsequent development of storage rots in packed fruit and (b) populations of fungi and yeasts on the surface of the apples.

\section{METHODS}

One hundred and ninety two crates of $65 \mathrm{cv}$. Braeburn apples were stored at $0.5^{\circ} \mathrm{C}$ for $1,3,4,7,8$ and 18 weeks after harvest. After each storage period, 32 crates were removed and half were subjected to artificial wounding. The skin of each punctured apple was broken with a sterile bamboo skewer to simulate a stem-puncture wound with a diameter of $2 \mathrm{~mm}$. Wounding treatments were applied immediately before washing fruit.

Washing treatments were applied after 3, 4, 7 and 8 weeks initial storage (Table 1). During each washing treatment, four replicates of four crates per wounding treatment 
were washed, using the washing facilities of commercial packhouses. The four replicates of punctured and undamaged cv. Braeburn apples were separated by cv. Granny Smith apples, and were washed $15 \mathrm{~min}$ apart. The apples spent approximately $5 \mathrm{~min}$ in the washing water and were subjected to approximately $20 \mathrm{sec}$ of washing at 550-750 kpa. The concentration of fungi and yeasts in the washing water varied widely (Table 1).

In addition, after 1 and 18 weeks initial storage (postharvest treatments A and F, respectively), 32 crates of apples were removed and, in each case, half were subjected to artificial wounding as previously described, but these apples remained unwashed. The unwashed control treatments were implemented before and after the washing treatments, to determine the effect of the initial storage time on fruit decay.

After each postharvest treatment, the apples were packed in apple boxes lined with a polyliner ( $80 \mathrm{apples} / \mathrm{box}$, four replicates of three boxes/wounding treatment). The boxes were placed in a commercial cool store at $0.5^{\circ} \mathrm{C}$. The apples were assessed twice, after a further 13 and 17 weeks storage, except for those of treatment $F$, which were assessed only once, after 13 weeks storage. Storage rot incidence was determined as the percentage of apples with decay. Apples with decay were examined using a dissecting microscope and tissue was examined using a compound microscope to identify the fungi. If no identification could be made, mycelium or spores were transferred onto potato dextrose agar (Merck) containing ampicillin $(50 \mu \mathrm{g} / \mathrm{ml})$ and streptomycin $(100 \mu \mathrm{g} / \mathrm{ml}$; antibiotic PDA) and incubated at $20^{\circ} \mathrm{C}$, for further analysis of cultural characteristics.

TABLE 1: Average concentrations of fungi and yeasts (colony forming units/ml) in water used for postharvest apple washing. Washed and unwashed postharvest treatments were applied after the apples had been stored for up to 18 weeks.

\begin{tabular}{lccc}
\hline Postharvest treatment & $\begin{array}{c}\text { Initial storage time } \\
\text { (weeks after harvest) }\end{array}$ & $\begin{array}{c}\text { Fungi } \\
(\mathrm{cfu} / \mathrm{ml})\end{array}$ & $\begin{array}{c}\text { Yeasts } \\
(\mathrm{cfu} / \mathrm{ml})\end{array}$ \\
\hline A (unwashed) & 1 & - & - \\
B & 3 & 38 & 0.3 \\
C & 4 & 450 & 29,000 \\
D & 7 & 2400 & 78,000 \\
E & 8 & 1450 & 230,000 \\
F (unwashed) & 18 & - & - \\
\hline
\end{tabular}

\section{Microbial enumeration}

The concentration of fungi and yeasts in the water that was used for postharvest apple washing (Table 1) was determined by collecting two water samples before the washing treatment and two water samples after the washing treatment. The washing water was serially diluted $\left(0\right.$ to $\left.10^{-4}\right)$ and plated in quadruplicate onto antibiotic PDA. Fungal and yeast colonies were counted after 1 week incubation at $20^{\circ} \mathrm{C}$.

Before and after each postharvest washing treatment, four samples of four undamaged apples and four samples of four punctured apples (16 samples per postharvest washing treatment), were collected in 16 plastic zip-bags for microbial enumeration of the fructosphere. The surface area of the apples was calculated using the formula of Clayton et al. (1995). To prevent the bags from being punctured, the stalks were removed and the apples were returned to the plastic zip-bags (four apples per bag). To each bag, 100 $\mathrm{ml}$ of sterile phosphate buffer ( $100 \mathrm{mM}$ potassium phosphate $+0.05 \%$ Tween $\left.{ }^{\circledR} 80\right)$ was added, and the bag was shaken vigorously by hand for 2 min, making sure all apples had equal exposure to the buffer (M. Walter, pers. comm.). The buffer was serially diluted $\left(0\right.$ to $\left.10^{-3}\right)$ and plated in duplicate onto antibiotic PDA. Fungal and yeast colonies were counted after 1 week incubation at $20^{\circ} \mathrm{C}$. 
In addition, 16 samples of four apples (eight samples of undamaged and eight of punctured apples) were collected from the crates of apples that remained unwashed (treatment A only). Half of these samples were collected before the apples were packed in apple boxes and the remaining samples were collected after the apples had been packed. The microbial enumeration of the fructosphere was determined as described above.

\section{Statistical analysis}

Data were subjected to angular transformation for analysis. Analysis of Variance (ANOVA) and Fisher's Protected Least Significant Differences of Means (LSD, $\alpha=0.05$ ) were used to determine statistical differences in storage rot incidence of apples between treatments. Main plots were groups of 32 crates of apples (2080 apples), to which a postharvest treatment was applied and subplots were groups of four crates of apples, to which a wounding treatment was applied. There was no replication of main plots. Therefore, it was not possible to test the main effect of the postharvest treatment.

ANOVA and Fisher's Protected LSD $(\alpha=0.05)$ were also used to determine statistical differences in microbial populations on apples between treatments, after logarithmic transformation of the data. Main plots were groups of 16 samples of apples (64 apples), to which a postharvest treatment was applied and subplots were samples of four apples, to which a washing treatment was applied. There was no replication of main plots. Therefore, it was not possible to test the main effect of the postharvest treatment.

Regression analysis was used to determine the relationship between the concentration of fungi and yeasts in washing water and storage rot incidence of apples that were washed in this water. Similarly, relationships between the microflora on apples after the washing treatment and both storage rot incidence and the microbial concentration in the water were determined.

\section{Storage rots}

\section{RESULTS}

Large differences were observed between the different postharvest treatments after storage (Fig. 1). Apples washed in water with a low concentration of fungi and yeasts (treatment B) had very low storage rot incidence and there was no significant difference between the punctured and the uninjured apples. A high incidence of storage rot was observed in apples that were washed in water with a high concentration of fungi and yeasts (treatments C, D and E). In these treatments, punctured apples had a significantly higher incidence of storage rot than did the uninjured control apples $(\mathrm{P}<0.01)$. Punctured apples that were washed in water containing the highest concentration of fungi and yeasts (treatments D and E) had the highest rot incidences. Unwashed apples (treatments A and F) had a low incidence of rots after storage and similar rot incidences were observed in the two unwashed treatments, regardless of the initial storage time of the apples (Fig. 1).

The symptoms of the majority of rots (91-94\%) in apples that were punctured and subsequently washed, were consistent with rots caused by Penicillium spp. No other fungi were detected on these apples. The remaining rots were apparently caused by Mucor spp., Pezicula spp., Colletotrichum spp., Botryospheria spp., Phoma spp., Botrytis spp., Cladosporium spp., Fusarium spp., Alternaria spp. and some fungi and yeasts for which a clear identification was not possible. The same species of fungi that were present on the rots of punctured apples, were also present on the rots in uninjured apples, except that only $10-50 \%$ of these rots were apparently caused by Penicillium spp. Penicillium spp. were also the only fungi detected in the majority of rots $(55 \%)$ in apples of the unwashed treatments; there was no difference between the punctured and undamaged apples. The remaining rots in the unwashed treatments were caused by some fungi and yeasts for which a clear identification was not possible, although Pezicula spp. and Fusarium spp. were also found. None of the unwashed apples had rot caused by Mucor spp. 


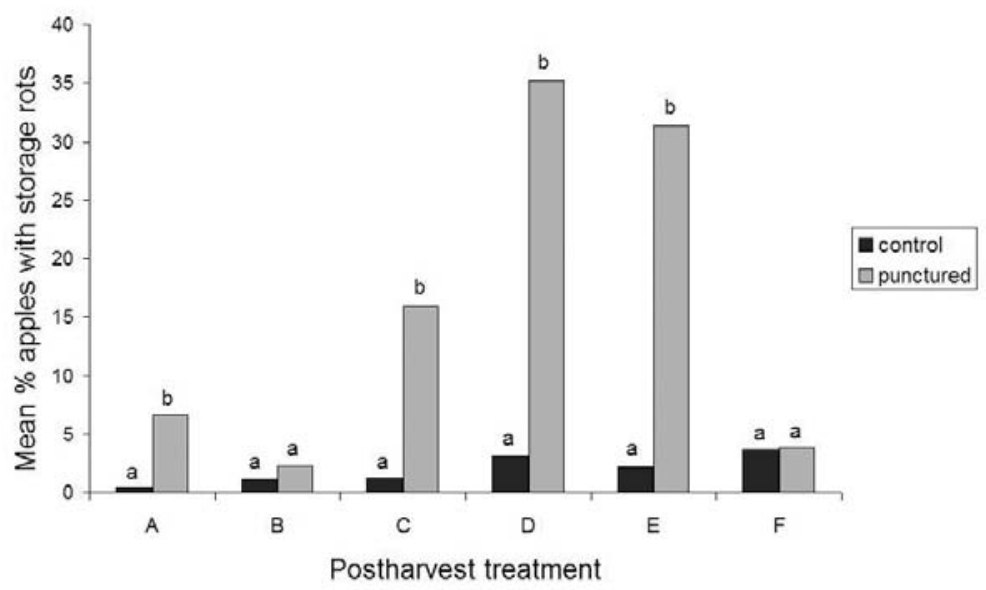

FIGURE 1: Mean incidence of storage rot (\% apples with rots) of punctured and uninjured apples exposed to six postharvest treatments, after 13 (treatment $\mathrm{F}$ ) or 17 weeks storage (treatments $\mathrm{A}-\mathrm{E}$ ) at $0.5^{\circ} \mathrm{C}$. Means with the same letter within each postharvest treatment are not significantly different $(\alpha=0.05, P<0.01)$.

\section{Apple microflora}

The majority of the fungi that were isolated from apple surfaces were Cladosporium spp. and unidentified mycelia sterilia. Other commonly isolated fungi included Alternaria spp., Penicillium spp., Epicoccum spp., Phomopsis spp., Mucor spp., Phoma spp. and Fusarium spp. The same fungal species were found on apples that had been washed as on those that had remained unwashed. These fungi were also isolated from the washing water.

The average number of fungi on the different batches of apples before they were washed varied between 174 and $740 \mathrm{cfu} / \mathrm{cm}^{2}$, while the average number of yeasts varied between $1 \times 10^{4}$ and $9 \times 10^{4} \mathrm{cfu} / \mathrm{cm}^{2}$. After the various washing treatments, the average number of fungi on the apples was reduced to between 21 and $144 \mathrm{cfu} / \mathrm{cm}^{2}$, while the average number of yeasts varied between $2.6 \times 10^{3}$ and $2 \times 10^{4} \mathrm{cfu} / \mathrm{cm}^{2}$. In all treatments, the numbers of fungi and yeasts on the apple surface were significantly reduced after washing (Figs $2 \mathrm{a} \& \mathrm{~b} ; \mathrm{P}<0.01$ ).

\section{Relationships between water microflora and post-washing apple microflora and storage rots}

Punctured apples that had been washed in water containing few microbial contaminants exhibited lower storage rot incidence than did those washed in water containing high concentrations of yeasts and fungi. A linear relationship was identified between the concentration of fungal contaminants in washing water and the incidence of storage rot in punctured apples (Fig. 3a).

A linear relationship was also detected between the number of fungi detected on the apple surface post-washing and storage rot incidence in punctured apples. Punctured apples with few fungi on their surface after the washing treatment exhibited lower storage rot incidence than did apples with large numbers of fungal cfus post-washing (Fig. 3b). 
(a)
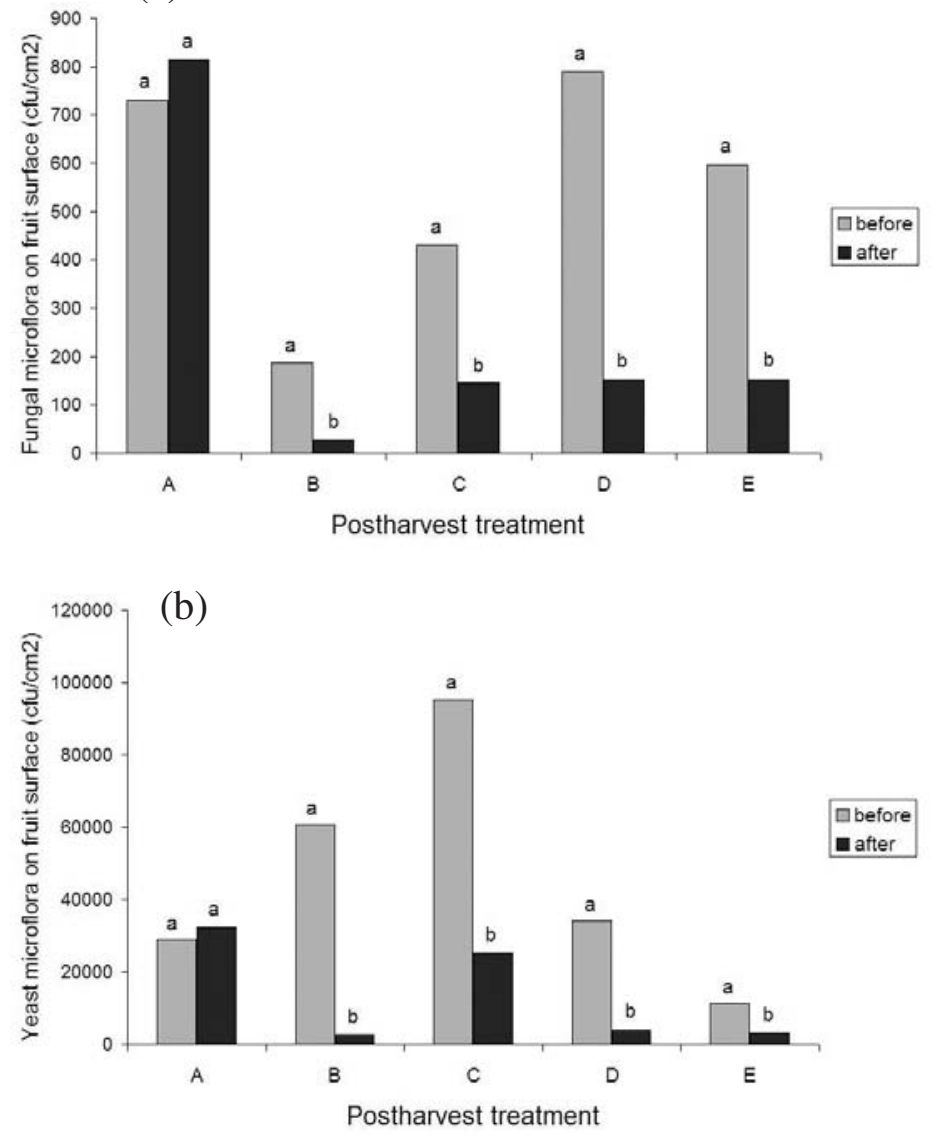

FIGURE 2: Mean numbers of micro-organisms on apples before and after each of five postharvest treatments. (a) fungal colony forming units (cfu) $/ \mathrm{cm}^{2}$ and (b) yeast $\mathrm{cfu} / \mathrm{cm}^{2}$. Means with the same letter within each postharvest washing treatment are not significantly different $(\alpha=0.05, P<0.01)$.

The fungal microflora on the apple surface after a washing treatment was dependent on the concentration of micro-organisms in the water. Very few fungi were isolated from apples that were washed in water with low numbers of micro-organisms (e.g. treatment B), whereas large numbers of fungi were isolated from apples washed in water containing high concentrations of fungi (e.g. treatments $\mathrm{D}$ and $\mathrm{E})$. A linear relationship was identified (data not shown): $\log \mathrm{Y}=0.32+0.57 * \operatorname{LogX}\left(\mathrm{R}^{2}(\operatorname{adj})=0.88, \mathrm{P}<0.0001\right)$, where $\mathrm{Y}$ is the post-washing fungal microflora on punctured apple surfaces and $\mathrm{X}$ is the concentration of fungal contaminants in the water. The standard errors of the intercept and slope of this regression line were 0.15 and 0.05 , respectively. However, when examining the effect of 

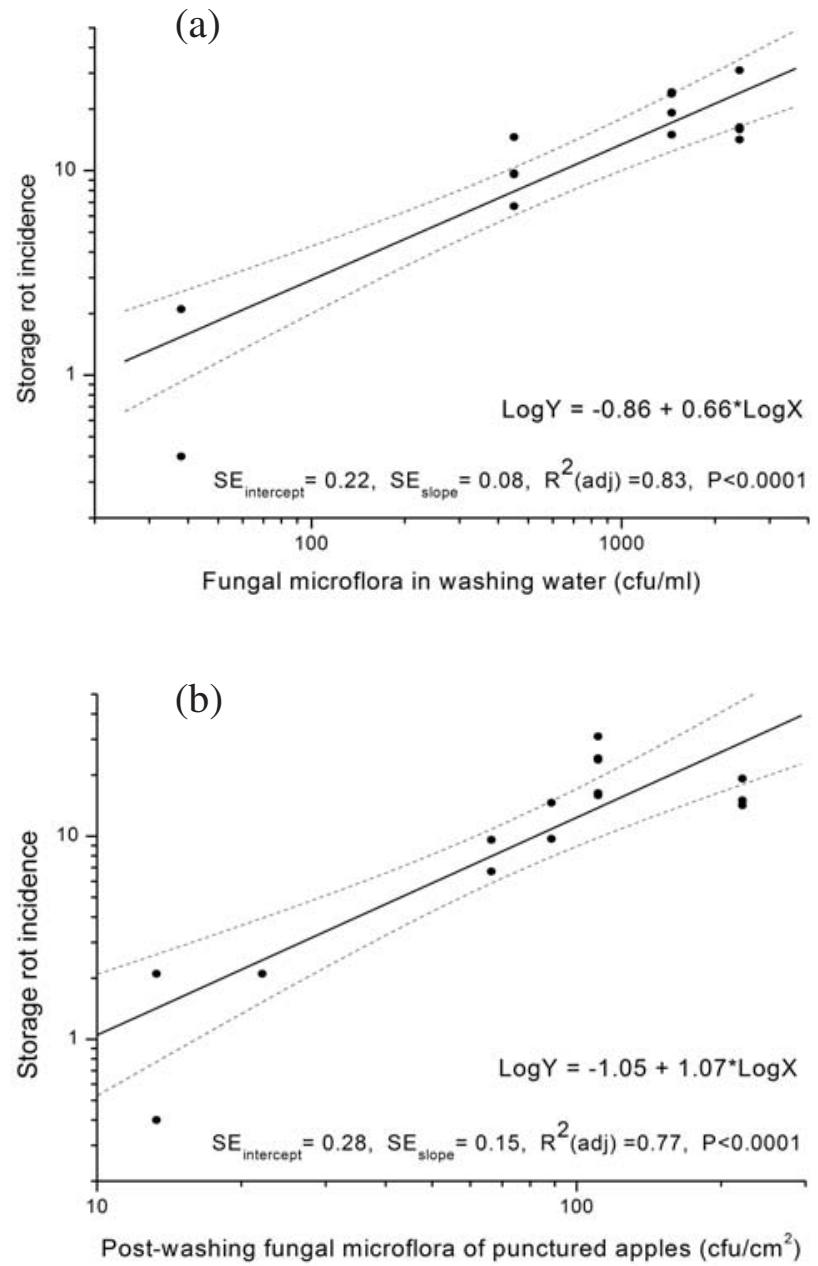

FIGURE 3: Linear relationship between log-transformed storage rot incidence in punctured apples after 13 weeks of storage and log-transformed fungal microflora (a) in postharvest washing water and (b) on apples post-washing treatment. The broken lines indicate the upper and lower $\mathbf{9 5 \%}$ confidence limits of the fitted line.

microbe concentration in washing water on the fungal microflora of all apples (punctured and uninjured), a slightly different linear relationship was identified, with a smaller $\mathrm{R}^{2}$ value (data not shown), described by the formula: $\log Y=0.62+0.48 * \log X\left(\mathrm{R}^{2}(\operatorname{adj})\right.$ $=0.62, \mathrm{P}<0.0001)$, where $\mathrm{Y}$ is the post-washing fungal microflora on apple surfaces and $\mathrm{X}$ is the concentration of fungal contaminants in washing water. The standard errors of the intercept and slope of this regression line were 0.19 and 0.07 , respectively. 
No relationship was detected between storage rot incidence on uninjured apples and the concentration of micro-organisms in washing water, or apple surface microflora. Similarly, no relationship was detected between storage rot incidence on unwashed apples (both punctured and uninjured) and apple surface microflora. In addition, no relationship was detected between storage rot incidence on apples and yeast concentration in washing water or on the apple surface.

\section{DISCUSSION}

Postharvest washing did not alter the incidence of storage rots of uninjured apples, regardless of the concentration of fungal pathogens in the water. In contrast, there was a high correlation between the concentration of fungi in washing water and the subsequent storage rot incidence of punctured apples washed in this water. Apples with a puncture wound were much more prone to rot when washed in water containing a high concentration of fungi, while postharvest washing of punctured fruit in water containing few fungi, resulted in very low rot incidence, similar to that in uninjured and/or unwashed fruit. This indicates that rot-causing fungi can be introduced to wounds in fruit during wash treatments and subsequently cause decay.

Penicillium spp. were present on the vast majority of rots in apples that were punctured and subsequently washed, and no other fungi were identified on most of these apples. This is not surprising, since Penicillium spp. are ubiquitous and commonly cause rot in apples and other fruit (M. Walter, pers. comm.).

The number of fungi and yeasts recovered from the surface of unwashed fruit varied widely between postharvest treatments. It is possible that the vigour with which the apples were hand-shaken to remove the micro-organisms, varied between postharvest treatments, resulting in these differences. However, large variations in micro-organism populations on the surface of fruits and vegetables haves also been recorded in the literature. For example, Krishna et al. (2001) detected $5 \times 10^{3}$ and $2 \times 10^{5} \mathrm{cfu} / \mathrm{cm}^{2}$ for fungi and yeasts on unwashed squash, while Pao \& Brown (1998) estimated fungal and yeast counts on unwashed oranges of $2 \times 10^{3} \mathrm{cfu} / \mathrm{cm}^{2}$, and Chun \& McDonald (1987) estimated microbial populations of $6 \times 10^{3}-1 \times 10^{4}$ and $2-5 \times 10^{3} \mathrm{cfu} / \mathrm{cm}^{2}$ for fungi and yeasts on grapefruit. The fungal populations on the surfaces of unwashed apples in this study were much smaller than those on squash or citrus, but the yeast populations on the unwashed apples were greater than those on citrus fruit and smaller than those on squash.

The numbers of fungi and yeasts on the apple surface were significantly reduced after each washing treatment, by approximately a factor 5. Similarly, when oranges and tangerines were washed, the fungal and yeast counts were reduced by a factor 20 , from $2 \times 10^{3}$ to approximately $1 \times 10^{2} \mathrm{cfu} / \mathrm{cm}^{2}$ (Pao \& Brown 1998). However, little difference was observed in populations of fungi and yeasts on washed or unwashed squash (Krishna et al. 2001).

A correlation was identified between the post-washing fungal population on the apple surface and the incidence of storage rot in punctured apples. Punctured apples with larger populations of fungi post-washing displayed a higher storage rot incidence. Despite the observation that washing significantly reduced the number of fungi on the apple surface, both the incidence of storage rot and the remaining fungal population on the apple surface were larger when punctured apples were washed in water containing high fungal concentrations, than when washed in water containing few fungi. The yeast population in washing water or on the apple surface did not appear to influence the incidence of apple storage rot.

In order to minimise the risk of storage rots after apple washing treatments for insect removal, packhouse operators are advised to regularly monitor the microbial status of their wash water and to either change it regularly or use appropriate sanitisers to reduce the concentration of rot causing micro-organisms. 


\section{ACKNOWLEDGEMENTS}

We wish to thank the packhouses and coolstores that were involved in this research, for generously providing their time and use of their equipment. We also acknowledge and thank Pipfruit New Zealand Inc. for funding the work, and the many HortResearch people who have contributed to the success of this research.

\section{REFERENCES}

Bartz JA 1999. Washing fresh fruits and vegetables: lessons from treatment of tomatoes and potatoes with water. Dairy, Food and Environmental Sanitation 19 (12): 853-864.

Chun D, McDonald RE 1987. Seasonal trends in the population dynamics of fungi, yeasts, and bacteria on fruit surface of grapefruit in Florida. Proceedings of the Florida State Horticultural Society 100: 23-25.

Clayton M, Amos ND, Banks NH, Morton RH 1995. Estimation of apple fruit surface area. New Zealand Journal of Crop and Horticultural Science 23: 345-349.

Krishna H, Carpenter A, Potter F 2001. Effect of washing additives on the incidence of rots and an enumeration of surface microbes in stored squash. New Zealand Plant Protection 54: 76-79.

Pao S, Brown GE 1998. Reduction of microorganisms on citrus fruit surfaces during packinghouse processing. Journal of Food Protection 61 (7): 903-906.

Spotts RA, Serdani M, Mielke EA, Bai JH, Chen PM, Hansen JD, Neven LG, Sanderson PG 2006. Effect of high-pressure hot water washing treatment on fruit quality, insects, and disease in apples and pears. Part II. Effect on postharvest decay of d'Anjou pear fruit. Postharvest Biology and Technology 40 (3): 216-220. 